\title{
Predicting patients at risk for pain associated with electrochemotherapy
}

Pietro Quaglino, Louise Wichmann Matthiessen, Pietro Curatolo, Tobian Muir, Giulia Bertino, Christian Kunte, Joy Odili, Roberta Rotunno, Alison Claire Humphreys, Valerie Letulé, Federica Marenco, Carol Cuthbert, Rikke Albret, Marco Benazzo, Francesca De Terlizzi \& Julie Gehl

To cite this article: Pietro Quaglino, Louise Wichmann Matthiessen, Pietro Curatolo, Tobian Muir, Giulia Bertino, Christian Kunte, Joy Odili, Roberta Rotunno, Alison Claire Humphreys, Valerie Letulé, Federica Marenco, Carol Cuthbert, Rikke Albret, Marco Benazzo, Francesca De Terlizzi \& Julie Gehl (2015) Predicting patients at risk for pain associated with electrochemotherapy, Acta Oncologica, 54:3, 298-306

To link to this article: http://dx.doi.org/10.3109/0284186X.2014.992546

() 2015 Informa UK Ltd.

\section{曲 Published online: 16 Jan 2015.}

Submit your article to this journal ๘

Џ Article views: 252

Q View related articles ¿

View Crossmark data $\nearrow$ 


\title{
Predicting patients at risk for pain associated with electrochemotherapy
}

\author{
PIETRO QUAGLINO ${ }^{1}$, LOUISE WICHMANN MATTHIESSEN ${ }^{2}$, PIETRO CURATOLO ${ }^{3}$, \\ TOBIAN MUIR ${ }^{4}$, GIULIA BERTINO ${ }^{5}$, CHRISTIAN KUNTE $^{6}$, JOY ODILI ${ }^{7}$, \\ ROBERTA ROTUNNO ${ }^{3}$, ALISON CLAIRE HUMPHREYS ${ }^{8}$, VALERIE LETULÉ 6 , \\ FEDERICA MARENCO ${ }^{1}$, CAROL CUTHBERT $^{7}$, RIKKE ALBRET $^{9}$, MARCO BENAZZO $^{5}$, \\ FRANCESCA DE TERLIZZI ${ }^{10} \&$ JULIE GEHL ${ }^{2}$
}

${ }^{1}$ Department of Medical Sciences, Dermatologic Clinic, University of Torino, Torino, Italy, ${ }^{2}$ Center for Experimental Drug and Gene Electrotransfer, Department of Oncology, Copenhagen University Hospital Herlev, Herlev, Denmark, ${ }^{3}$ Department of Dermatology and Plastic Surgery, Dermatologic Clinic, University of Rome "La Sapienza", Rome, Italy, ${ }^{4}$ Department of Reconstructive Plastic Surgery, Fames Cook University Hospital, Middlesbrough, UK, ${ }^{5}$ Department of Otolaryngology Head $\mathcal{G}$ Neck Surgery, University of Pavia, IRCCS Policlinico, San Matteo Foundation, Pavia, Italy, ${ }^{6}$ Department of Dermatology and Allergology, Ludwig-Maximilian University Munich, Munich, Germany, ${ }^{7}$ Department of Plastic Surgery, St. Georges Hospital, London, UK, ${ }^{8}$ Department of Oncology, James Cook University Hospital, Middlesbrough, UK, ${ }^{9}$ Department of Anaesthesiology, University of Copenhagen, Herlev Hospital, Herlev, Denmark and ${ }^{10}$ IGEA S.p.a., Via Parmenide, 10/A Carpi, Italy

\section{ABSTRACT}

Background. Electrochemotherapy describes the use of electric pulses to enhance chemotherapy uptake, and has proven highly efficient in treating cutaneous metastases. Patients referred for electrochemotherapy present with diverse clinical pictures, from multiple small lesions to large, ulcerated lesions. Post-electrochemotherapy pain has been observed in some patients. The objectives of this study were to evaluate pain scores before and after electrochemotherapy, and to investigate if patients at risk of post-procedure pain could be identified.

Methods. Seven cancer centres in the International Network for Sharing Practices on Electrochemotherapy (INSPECT) consecutively and prospectively reported to a common database. Electrochemotherapy consisted of intratumoural or intravenous injection of bleomycin, followed by delivery of electric pulses in local or general anesthesia.

Results. Of 121 patients 39\% had metastatic melanoma, 18\% squamous cell carcinoma, $16 \%$ breast cancer, $13 \%$ basalcell carcinoma, and 14\% other malignancies. Median size of the largest nodules was $2.3 \mathrm{~cm}$ (range $0.3-40 \mathrm{~cm})$. A majority of patients presented with low pain scores, and this continued through follow-up (74\%). A subset of patients had moderate $(13 \%)$ or severe pain $(13 \%)$ after treatment. Post-procedure pain was statistically significantly associated with: 1) moderate or severe pain before treatment $(\mathrm{p}<0.0001)$; 2$)$ size of the largest treated lesion $(\mathrm{p}<0.01) ; 3)$ previous irradiation $(\mathrm{p}<0.02)$; and 4$)$ high treatment current value $(\mathrm{p}<0.0001)$.

Conclusion. The majority of patients had no or mild pain after electrochemotherapy. Patients at risk for post-procedure pain could be identified at the pre-treatment visit, and/or at the time of treatment, enabling a pain management strategy for this group.

Electrochemotherapy is a new but already well established local treatment modality for disseminated cutaneous metastases of different malignancies including melanoma, squamous-cell and basal-cell carcinoma, breast cancer and Kaposi sarcoma [1-17]. A recent meta-analysis showed an overall response rate for electrochemotherapy of cutaneous metastases at $75 \%$, with a complete response rate of $47 \%$ [18].This promising technique combines the antitumour activity of non-permeant (e.g. bleomycin) anticancer drugs

Correspondence: J. Gehl, Department of Oncology, Copenhagen University Hospital Herlev, Herlev Ringvej 75, 2730 Herlev, Denmark. Tel: +45 38682981. E-mail: Julie.gehl@regionh.dk

(C) 2015 Informa UK Ltd. This is an open-access article distributed under the terms of the CC-BY-NC-ND 3.0 License which permits users to download and share the article for non-commercial purposes, so long as the article is reproduced in the whole without changes, and provided the original source is credited. 
with short intense electrical pulses [19,20]. Electric pulses are delivered locally and increase cell permeability enhancing drug uptake into tumour cells, thus increasing the intracellular concentration and toxicity of the administered agent. Consistently, impressive clinical activity has been reported, with high complete response rates in treated cutaneous metastases. Besides the clinical activity in terms of response rates, electrochemotherapy has been shown to exert a palliative role in reducing discomfort and pain from cutaneous metastases $[9,12]$.

Patients referred for electrochemotherapy present with diverse disease manifestations; from the melanoma patient with multiple small cutaneous metastases, to the patient with cutaneous recurrence of breast cancer up to $40 \mathrm{~cm}$, as evidenced in this study. In earlier studies, where smaller cutaneous metastases were treated, pain has not been reported as a significant issue $[4,9,10]$. However, as the technology has been applied to patients with larger cutaneous metastases, pain has been reported as a more frequent side effect [12].

The International Network on Sharing Practices for Electrochemotherapy (INSPECT) database was formed to be able to answer questions of importance for use of electrochemotherapy. The objectives of this study were to evaluate pain scores before and after electrochemotherapy, and to investigate if a subset of patients at risk of pain could be identified.

\section{Patients}

Patients were treated consecutively at seven institutions in the INSPECT network (Rome, Middlesbrough, Turin, Pavia, Munich, London, Copenhagen). Centres included patient data prospectively to the same database. Approval from ethics committee, and data protection authority was according to each institution. Clinical information retrieved by the database included: demographics; type of tumour; number of treated lesions, site and size of the largest lesion, previous irradiation (it was registered whether a cutaneous metastasis was in a previously irradiated field, but not what dose or fractionation had been given), duration of follow-up, possible retreatment with electrochemotherapy at subsequent time point.

Patients treated had histologically proven cancer with measurable cutaneous metastases, or mucosal lesions, suitable for application of electric pulses, or had primary non-melanoma skin cancer, where other options were exhausted or not possible. Patients had been offered standard treatment options, were $\geq 18$ years old, had ECOG performance status $\leq 2$, a life expectancy of at least three months, and if fertile were using adequate contraception. Patients were not treated if they previously had allergic reactions to bleomycin or to any of the components required for anaesthesia, if the cumulative dose of $250 \mathrm{mg}$ bleomycin $/ \mathrm{m}^{2}$ (400.000 IU bleomycin $/ \mathrm{m}^{2}$ ) had previously been exceeded, had chronic renal dysfunction (serum creatinine $>150 \mu \mathrm{mol} / \mathrm{l})$ or acute lung infection.

\section{Methods}

\section{Procedure}

Electrochemotherapy was performed based on the standard operating procedures published in 2006 $[12,21]$. Briefly, bleomycin (manufacturer according to practice of the institution) was administrated either intratumourally (i.t.) using $1000 \mathrm{IU} / \mathrm{ml}$ or intravenously (i.v.) using $15.000 \mathrm{IU} / \mathrm{m}^{2}$, intratumoural or intravenous dosage was chosen depending on the number of cutaneous metastases to be treated and size of metastases. Likewise, local anesthesia was used for small or few metastases, whereas general anaesthesia was preferred for multiple metastases, large metastases $(>3 \mathrm{~cm})$, metastases adhering to the periosteum or situated in sensitive regions (e.g. face and scalp), and in accordance with patient preference. Depending on clinician's choice, one of the following electrodes was used: 1) Type I electrodes: two plates with a $6 \mathrm{~mm}$ gap between the plates; 2) Type II electrodes: two parallel rows of needles with $4 \mathrm{~mm}$ between rows; 3) Type III electrodes: a hexagonal array with $7.9 \mathrm{~mm}$ between the needles. Electric pulses (eight pulses of $100 \mu \mathrm{s}$ duration) were delivered using a square wave electroporator (IGEA, Carpi, Italy). The applied voltage relative to distance between electrodes was $1.3 \mathrm{kV} / \mathrm{cm}$ for plate electrodes and $1.0 \mathrm{kV} / \mathrm{cm}$ for needle electrodes, i.e. for the type II needle electrode with a 4 $\mathrm{mm}$ gap the applied voltage was $400 \mathrm{~V}$. For type I and II electrodes, the pulses are applied with $1 \mathrm{~Hz}$ or 5 $\mathrm{kHz}$, whereas for type III electrodes, pulses can only be applied with $5 \mathrm{kHz}$. After electrochemotherapy, the treated metastases were covered with standard dressings where necessary.

\section{Response evaluation}

Tumour response was evaluated according to the Response Evaluation Criteria in Solid Tumours (RECIST version 1.0), modified to only include response of the treated cutaneous metastases. A maximum of seven cutaneous metastases per patient (including the largest tumour) were registered as target lesions, as in previous studies $[4,10]$.

\section{Pain assessment}

Pain assessment was performed at four time points: before treatment, within 24 hours after treatment, thereafter within 45 days from treatment and after 
more than 45 days from treatment. Pain intensity was evaluated using the Numeric Rating Scale (NRS) for pain [22]. NRS is a uni-dimensional 11-point numeric scale in which the patient is asked to indicate a whole number (between "0" as "no pain" and "10" as "worst pain") in a horizontal bar. Respondents were asked to indicate their average pain intensity related to cutaneous metastases. We used a previously published cut-off on NRS score [23]: 0-2 mild pain, 3-4 moderate pain, 5-10 severe pain. Pain medication was registered as 'none', 'sometimes', 'controlled by non-opioids', 'controlled by opioids', 'uncontrolled', or 'unknown'.

\section{Statistics}

SPSS (Statistical Packages for Social Sciences) 15.0 was used. Continuous variables were expressed as mean, median, standard deviation and range, categorical variables as frequencies and percentages. Comparisons between couples of groups were performed with two-tailed heteroschedastic Student's t-test for continuous variables, and $\chi^{2}$-test with Yate's continuity correction. Comparison among the three pain groups were performed with ANOVA test (continuous variables) and $\chi^{2}$-test (categorical variables). Generalised linear model was applied for independent predictors of pain within 45 days after treatment: categorical variables were tested using a reference group (group "other diagnosis" versus: "metastatic melanoma", "breast cancer", "squamous cell carcinoma", "basal cell carcinoma"; group "abdomen, back, genitalia" versus: "upper/lower limbs", "head/ neck, scalp, intraoral", "chest”; group "previous irradiation" versus "no previous irradiation").

\section{Results}

\section{Patients}

A total of 124 patients were included, three were lost to follow-up due to: progressive disease (two patients) and death not related to procedure (one patient). A total of 121 patients with cutaneous metastases were included in this analysis from seven centres belonging to the INSPECT network: Rome $(\mathrm{n}=28)$, Middlesbrough $(\mathrm{n}=23)$, Turin $(\mathrm{n}=19)$, Pavia $(\mathrm{n}=18)$, Munich $(\mathrm{n}=14)$, London $(\mathrm{n}=11)$, Copenhagen $(\mathrm{n}=8)$. Accrual time was from July 2007 to May 2012. The main demographics and clinical characteristics of these patients are summarised in Table I. Figure 1 shows representative images of the various clinical presentations. The pain evaluation was available for all 121 patients before and at one or more points after electrochemotherapy. Figure 2 shows percentage of patients for whom pain data was available
Table I. Patient demography and treatment choices.

\begin{tabular}{|c|c|c|}
\hline Pre-treatment visit (121 patients) & No & $\%$ \\
\hline \multicolumn{3}{|l|}{ Gender } \\
\hline- male & 53 & $44 \%$ \\
\hline - female & 68 & $56 \%$ \\
\hline \multicolumn{3}{|l|}{ Age (years) } \\
\hline- median & 72 & \\
\hline - range & $39-95$ & \\
\hline \multicolumn{3}{|l|}{ Diagnosis } \\
\hline - Metastasis of malignant melanoma & 47 & $39 \%$ \\
\hline - Squamous cell carcinoma & 22 & $18 \%$ \\
\hline - Breast cancer & 19 & $16 \%$ \\
\hline - Basal cell carcinoma & 16 & $13 \%$ \\
\hline - Kaposi sarcoma & 6 & $5 \%$ \\
\hline - Sarcoma & 5 & $4 \%$ \\
\hline - Adenocarcinoma (not breast) & 3 & $2 \%$ \\
\hline - Merkel cell carcinoma & 1 & $1 \%$ \\
\hline- others $^{\mathrm{a}}$ & 2 & $2 \%$ \\
\hline \multicolumn{3}{|l|}{ Site of the largest nodule } \\
\hline - Head and neck & 36 & $30 \%$ \\
\hline - scalp & 1 & $1 \%$ \\
\hline - intraoral & 3 & $3 \%$ \\
\hline - chest & 32 & $26 \%$ \\
\hline - abdomen & 6 & $5 \%$ \\
\hline - back & 4 & $3 \%$ \\
\hline - genitalia & 3 & $2 \%$ \\
\hline - upper limbs & 5 & $4 \%$ \\
\hline - lower limbs & 31 & $26 \%$ \\
\hline \multicolumn{3}{|l|}{ Number of treated nodules (per patient) ${ }^{\mathrm{b}}$} \\
\hline - median & 2 & \\
\hline - range & $1-7$ & \\
\hline \multicolumn{3}{|l|}{ Size of the largest nodule $(\mathrm{cm})$} \\
\hline - median & 2.3 & \\
\hline - range & $0.3-40$ & \\
\hline \multicolumn{3}{|l|}{ Bleomycin admninistration } \\
\hline - Local & 17 & $14 \%$ \\
\hline - Systemic & 104 & $86 \%$ \\
\hline \multicolumn{3}{|l|}{ Anaesthesia } \\
\hline - Local & 49 & $40 \%$ \\
\hline - General & 72 & $60 \%$ \\
\hline \multicolumn{3}{|l|}{ Electrodes used } \\
\hline - Plate & 7 & $6 \%$ \\
\hline - Row needle & 35 & $29 \%$ \\
\hline - Hexagonal & 69 & $57 \%$ \\
\hline Combination & 10 & $8 \%$ \\
\hline
\end{tabular}

${ }^{\mathrm{a}}$ endometrial cancer, metastatic metatypical cell carcinoma; bonly up to 7 nodules registered per patient.

at the respective time points, and Table II lists pain medication at the respective time points. Twenty-one patients received a subsequent treatment with electrochemotherapy; the median time between two sessions was 63 days (range 16 days -5.6 months).

\section{Reported pain scores before and after treatment}

Pain assessment was performed using standard NRS score before treatment, within 24 hours after treatment, within 45 days from treatment and after more than 45 days from treatment.

A majority of patients did not experience pain before treatment $(60 \%$ with NRS score $=0)$, this 

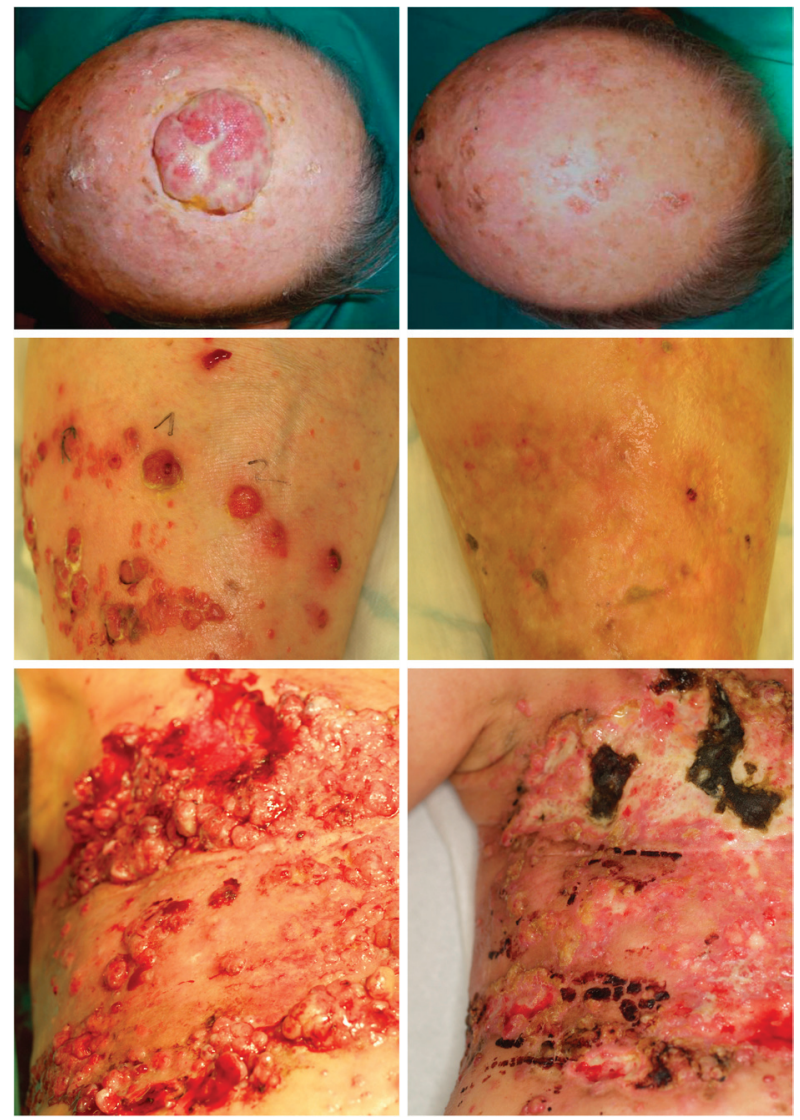

Figure 1. Clinical characteristics of patients. Patients referred for electrochemotherapy present with quite different clinical problems. Top panels: 93-year-old male patient with squamous cell carcinoma of the scalp before treatment (left) and after three treatments (right), treated at University of Rome. Middle panels: 88-year-old female patient with multiple metastases of malignant melanoma on left lower leg, recurrence after several other treatments including surgery and radiotherapy (left side). Four months after one session with electrochemotherapy (right side) all cutaneous and subcutaneous metastases regressed. Typical hyperpigmentation and fibrosis of the skin. Lower panels; 58-year-old female patient with extensive relapse and metastases of breast cancer of the chest wall, accompanied by extensive bleeding and malodour (left side). Eight weeks after first electrochemotherapy session, regression of exophytic tumors, cessation of bleeding and malodur. Development of new metastases at the border of the treated area. Latter two cases treated in Ludwig-Maximilian Institute, Munich.

percentage dropped to $43 \%$ within 24 hours after treatment, and rose again to $57 \%$ and $66 \%$, respectively, within 45 days and after 45 days from treatment (Figure 2). Patients presenting with larger tumours had higher pain scores before treatment (mean NRS in patients with largest metastasis over $3 \mathrm{~cm}$ was $2.3 \pm 2.6$, and for patients with smaller metastases $1.3 \pm 2.2, \mathrm{p}=0.02$ ).

Of the patients experiencing pain, the majority had scores from 1 to 3 (Figure 2).

Trends in NRS scores during treatment were coupled with the analysis of pain medications taken by the patients (Table II). The percentage of patients not taking pain medication increased after treatment, and it is noteworthy that only a small percentage of patients took opioids at baseline $(9.1 \%)$; and this percentage fell after treatment (Table II). Overall, patients needed less pain medication after treatment $(\mathrm{p}=0.0069)$.

\section{Correlation of pain scores with other factors}

A series of parameters potentially associated with the severity of pain within 45 days after treatment have been analysed. The results are shown in Table III. Age, gender, type of tumour, site of cutaneous metastases were not associated with increased pain severity. Size of metastases and previous irradiation were associated with a significant increase in pain severity after electrochemotherapy $(p=0.008$ and $\mathrm{p}=0.014$, respectively). For parameters related to treatment, higher current value (more than $5 \mathrm{~A}$ ) was significantly associated to pain $(p<0.0001)$. A strong predictor of pain at follow-up was actually pain before treatment, and also within 24 hours after treatment $(\mathrm{p}<0.0001)$.

Multivariate analysis was also performed, and here pain before and after treatment were considered as numerical ordinal variables, as well as electric current intensity. The results of the model showed that significant independent predictors of high pain intensity within 45 days after electrochemotherapy are: pretreatment high pain intensity $(B=0.521 \pm 0.088$, $\mathrm{p}<0.0001)$, high current intensity $(\mathrm{B}=0.476 \pm 0.157$, $\mathrm{p}=0.002)$, diagnosis of melanoma $(\mathrm{B}=1.236 \pm 0.567$, $\mathrm{p}=0.029)$ and breast cancer $(\mathrm{B}=2.312 \pm 0.890$, $\mathrm{p}=0.009$ ) compared to other diagnoses (where $\mathrm{B}$ is the coefficient in the model).

\section{Tumour response}

Response data are listed in Table IV. Statistical analysis showed significant correlation between reported pain and tumour response $(p=0.0029)$.

\section{Discussion}

Electrochemotherapy is a new therapeutic procedure which is increasingly being used to treat cutaneous metastases from different tumours. Initially only smaller cutaneous tumours were reported to be treated $[1,24]$, but development of the technology and publication of standard operating procedures [21] as well as further clinical studies $[9,25]$ have led to treatment also of considerably larger cutaneous metastases [12].

As evidenced in the demography of the present patient population, metastases vary from very small $(3 \mathrm{~mm}$ ) to very large cutaneous metastases $(400 \mathrm{~mm})$, are of different histology and with various previous 

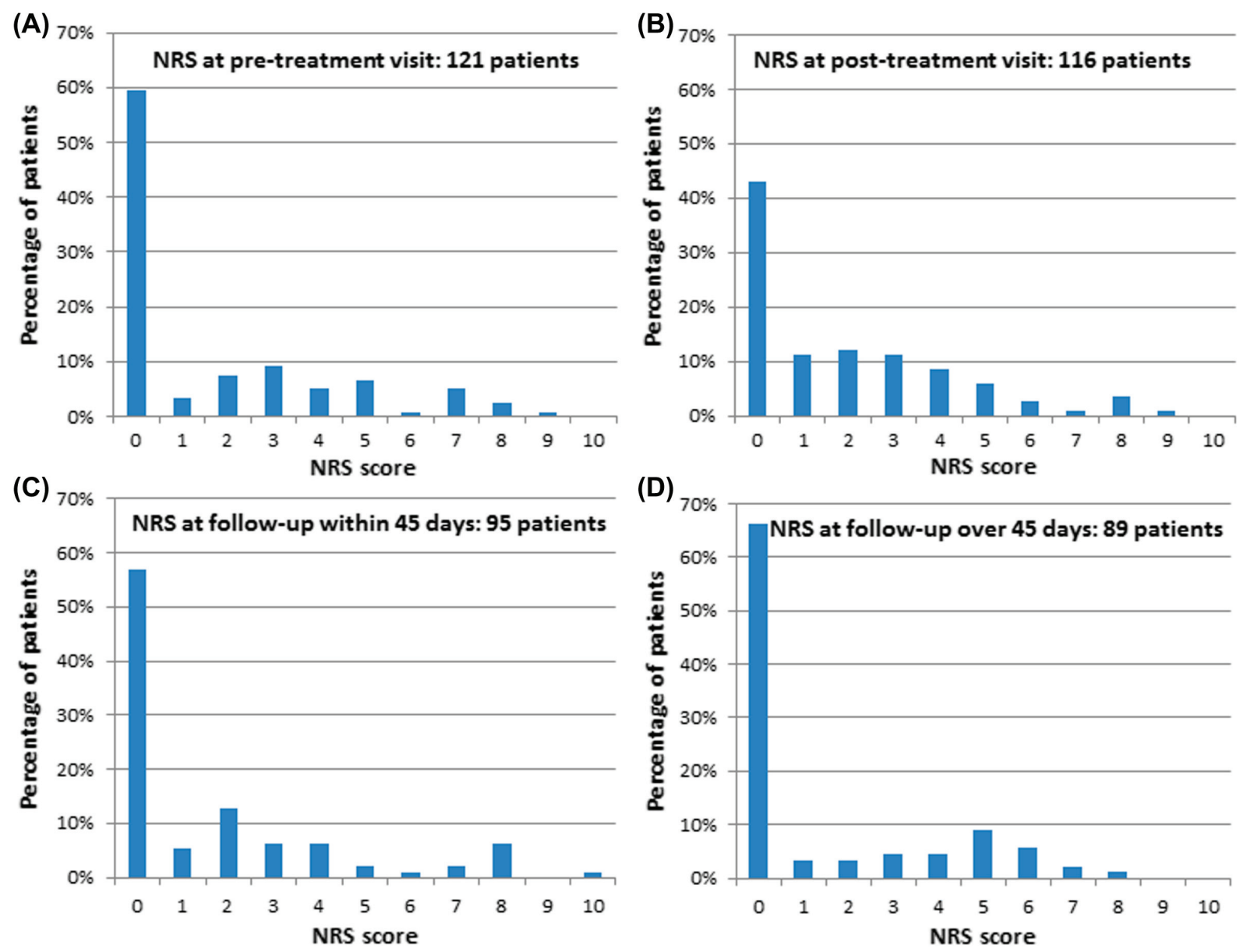

Figure 2. Percentage distribution of patients in relation to their pain score. The reported pain relating to treated cutaneous metastases using numeric rating scale (NRS) is illustrated in (A) before treatment, (B) within 24 hours from treatment - either after completion of treatment in local anaesthesia or before discharge from hospital in the case of general anaesthesia, (C) within 45 days from treatment, (D) after more than 45 days from treatment.

treatments. Figure 1 gives an impression of the diversity of clinical presentations.

Numerous studies have demonstrated the high clinical activity of electrochemotherapy in terms of both response rate and duration [1-16]. However, one of the issues which became evident, in particular when treating larger tumours, was that even though electrochemotherapy may reduce pain from cutaneous metastases [9], the procedure itself may also induce this symptom as a subset of patients can develop posttreatment pain [12]. Pain is treatable, and the understanding of the distribution, time of onset and duration, as well as the identification of patients more likely to experience pain after electrochemotherapy, allows rational therapeutic strategies for pain control.

Table II. Distribution of patients with regards to pain medication before electrochemotherapy, at follow-up within 45 days after treatment, and at follow-up after more than 45 days from treatment.

\begin{tabular}{|c|c|c|c|c|c|c|}
\hline \multirow[b]{2}{*}{ Pain medication } & \multicolumn{2}{|c|}{$\begin{array}{c}\text { Before } \\
\text { electrochemotherapy }\end{array}$} & \multicolumn{2}{|c|}{$\begin{array}{l}\text { At follow-up within } 45 \\
\text { days from treatment }\end{array}$} & \multicolumn{2}{|c|}{$\begin{array}{c}\text { At follow-up after more than } 45 \\
\text { days from treatment }\end{array}$} \\
\hline & $\mathrm{N}$ & $\%$ & $\mathrm{~N}$ & $\%$ & $\mathrm{~N}$ & $\%$ \\
\hline None & 44 & 36.4 & 45 & 46.4 & 52 & 56.5 \\
\hline Sometimes, controlled by non-opioids & 40 & 33.0 & 31 & 32.0 & 17 & 18.5 \\
\hline Controlled by non-opioids & 20 & 16.5 & 10 & 10.3 & 15 & 16.3 \\
\hline Controlled by opioids & 11 & 9.1 & 6 & 6.2 & 2 & 2.2 \\
\hline Uncontrolled & 3 & 2.5 & 4 & 4.1 & 5 & 5.4 \\
\hline Unknown & 3 & 2.5 & 1 & 1.0 & 1 & 1.1 \\
\hline Total & 121 & 100.0 & 97 & 100 & 92 & 100 \\
\hline
\end{tabular}


Table III. Pain intensity at follow-up within 45 days: association with parameters recorded at pre-treatment visit, and treatment data.

\begin{tabular}{|c|c|c|c|c|c|c|c|}
\hline NRS BY GROUPS & $0-2$ & & $3-4$ & & $5-10$ & & Statistics \\
\hline \multirow[t]{2}{*}{ TOTAL (95 patients) } & 71 & & 12 & & 12 & & \\
\hline & No & $\%$ & No & $\%$ & No & $\%$ & $\mathrm{p}$-Value \\
\hline \multicolumn{7}{|l|}{ Gender } & $\chi^{2}$ n.s. \\
\hline- male & 33 & $46 \%$ & 4 & $33 \%$ & 4 & $33 \%$ & $(\mathrm{p}=0.532)$ \\
\hline - female & 38 & $54 \%$ & 8 & $67 \%$ & 8 & $67 \%$ & \\
\hline \multicolumn{8}{|l|}{ Age (years) } \\
\hline- median & 74 & & 80 & & 74 & & ANOVA \\
\hline - range & $41-94$ & & $42-88$ & & $46-94$ & & n.s. \\
\hline- mean \pm st.dev. & $71.0 \pm 12.9$ & & $75.6 \pm 13.0$ & & $71.6 \pm 16.0$ & & $(\mathrm{p}=0.544)$ \\
\hline \multicolumn{8}{|l|}{ Diagnosis } \\
\hline - Metastasis of malignant melanoma & 22 & $31 \%$ & 8 & $67 \%$ & 5 & $42 \%$ & $\chi^{2}$ n.s. \\
\hline - Squamous cell carcinoma & 14 & $20 \%$ & 3 & $25 \%$ & 2 & $17 \%$ & $(\mathrm{p}=0.249)$ \\
\hline - Breast cancer & 10 & $15 \%$ & 1 & $8 \%$ & 3 & $25 \%$ & \\
\hline - Basal cell carcinoma & 11 & $16 \%$ & 0 & $0 \%$ & 1 & $8 \%$ & \\
\hline - Others* & 14 & $18 \%$ & 0 & $0 \%$ & 1 & $8 \%$ & \\
\hline \multicolumn{8}{|l|}{ Site of the largest nodule } \\
\hline - Head and neck (scalp, intraoral) & 28 & $39 \%$ & 3 & $25 \%$ & 5 & $42 \%$ & $\chi^{2}$ n.s. \\
\hline - Trunk (chest, abdomen, back, genitalia) & 24 & $35 \%$ & 3 & $25 \%$ & 2 & $17 \%$ & $(\mathrm{p}=0.414)$ \\
\hline - Limbs (upper limbs, lower limbs) & 19 & $26 \%$ & 6 & $50 \%$ & 5 & $41 \%$ & \\
\hline \multicolumn{8}{|l|}{ Size of the largest nodule $(\mathrm{cm})$ : } \\
\hline - median & 2.0 & & 5.3 & & 3.7 & & ANOVA \\
\hline - range & $0.3-20$ & & $0.4-12$ & & $0.7-40$ & & $\mathrm{p}=0.0080$ \\
\hline - mean \pm st.dev. & $3.8 \pm 4.3$ & & $5.7 \pm 4.9$ & & $9.7 \pm 12.7$ & & \\
\hline \multicolumn{8}{|l|}{ Current value } \\
\hline$-0-1.5 \mathrm{~A}$ & 9 & $15 \%$ & 3 & $25 \%$ & 0 & $0 \%$ & $\chi^{2}$ \\
\hline$-1.5-3 \mathrm{~A}$ & 31 & $52 \%$ & 0 & $0 \%$ & 1 & $8 \%$ & $\mathrm{p}<0.0001$ \\
\hline$-3-5 \mathrm{~A}$ & 12 & $20 \%$ & 5 & $42 \%$ & 2 & $17 \%$ & \\
\hline$->5 \mathrm{~A}$ & 8 & $13 \%$ & 4 & $33 \%$ & 9 & $75 \%$ & \\
\hline \multicolumn{8}{|l|}{ Previous irradiation } \\
\hline - yes & 8 & $13 \%$ & 3 & $25 \%$ & 6 & $50 \%$ & $\chi^{2}$ \\
\hline- no & 52 & $87 \%$ & 9 & $75 \%$ & 6 & $50 \%$ & $\mathrm{p}=0.014$ \\
\hline \multicolumn{8}{|l|}{ NRS pre-treatment } \\
\hline - median (range) & $0(0-8)$ & & $4(0-9)$ & & $5(0-8)$ & & ANOVA \\
\hline - mean \pm st.dev. & $0.9 \pm 1.6$ & & $3.8 \pm 3.0$ & & $4.7 \pm 2.6$ & & $\mathrm{p}<0.0001$ \\
\hline \multicolumn{8}{|l|}{ NRS post-treatment } \\
\hline - median (range) & $1(0-9)$ & & $4(0-8)$ & & $2(0-8)$ & & ANOVA \\
\hline- mean \pm st.dev. & $1.4 \pm 1.9$ & & $4.4 \pm 2.1$ & & $2.8 \pm 3.0$ & & $\mathrm{p}<0.0001$ \\
\hline
\end{tabular}

*others: 6 Kaposi sarcoma, 5 sarcoma, 2 adenocarcinoma (non-breast), 1 Merkel cell carcinoma, 1 other.

This study shows, that the majority of patients referred for electrochemotherapy come with low pain scores, and continue to have low pain scores after treatment (Figures 2, 3 and Table II-IV). Thus, of the 121 patients a majority of patients did not experience pain before treatment $(60 \%$ with NRS score $=0)$, this percentage dropped to $43 \%$ at within 24 hours after the procedure, and rose again to $57 \%$ and $66 \%$, respectively, within 45 days after treatment and after more than 45 days from treatment (Figure 2).

Thirty percent of patients reported NRS scores of 3 or higher before electrochemotherapy, indicating that some patients may have a need for intervention at first consultation. Interestingly, the data very

Table IV. Pain intensity at follow-up: relationship with the response per patient on the largest nodule.

\begin{tabular}{lcrrrrrr}
\hline NRS BY GROUPS & $0-2$ & & $3-4$ & & $5-10$ & & Statistics \\
\hline TOTAL (95 pts) & 71 & & 12 & & 12 & & \\
\hline & No & $\%$ & No & $\%$ & No & $\%$ & p-Value \\
\hline CR & 38 & $54 \%$ & 1 & $8 \%$ & 5 & $41 \%$ & \\
PR & 20 & $28 \%$ & 6 & $50 \%$ & 2 & $17 \%$ & $\chi^{2}$ \\
SD & 10 & $14 \%$ & 4 & $34 \%$ & 2 & $17 \%$ & $\mathrm{p}=0.0045$ \\
PD & 2 & $3 \%$ & 0 & $0 \%$ & 3 & $25 \%$ & \\
NA & 1 & $1 \%$ & 1 & $8 \%$ & 0 & $0 \%$ & \\
\hline
\end{tabular}



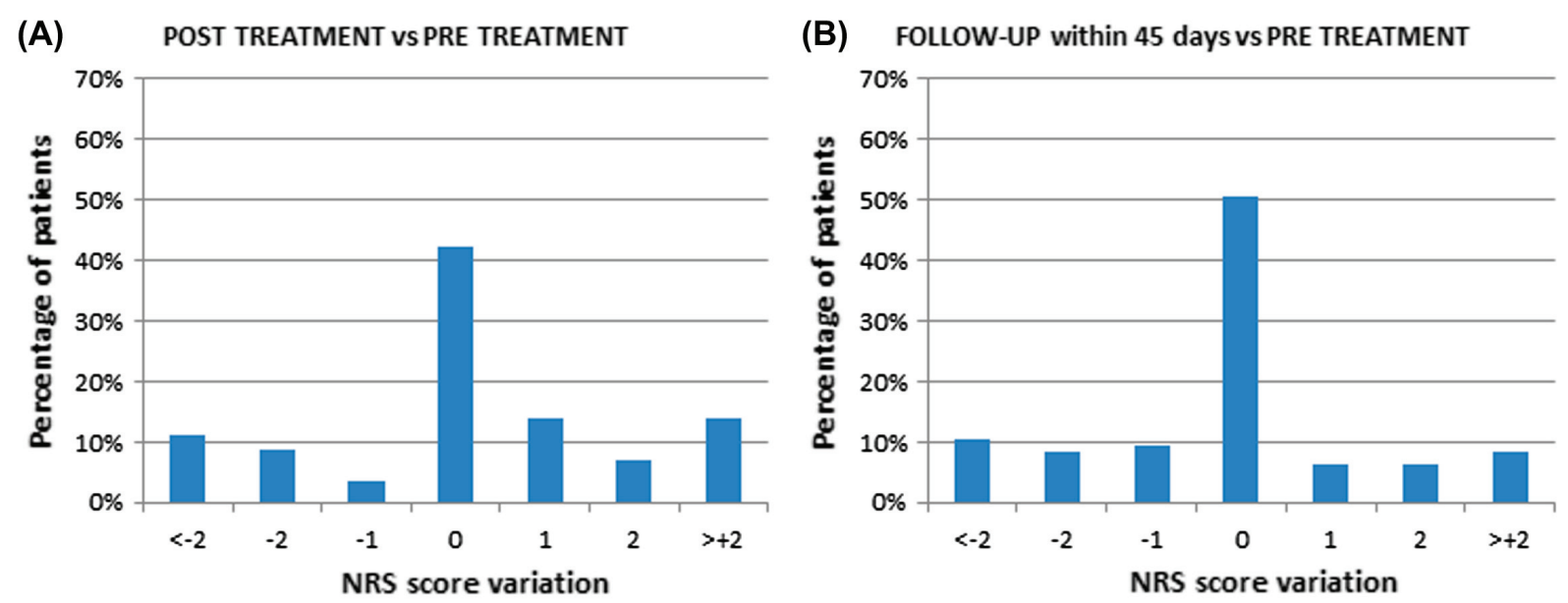

(C) FOLLOW-UP over 45 days vs PRE TREATMENT

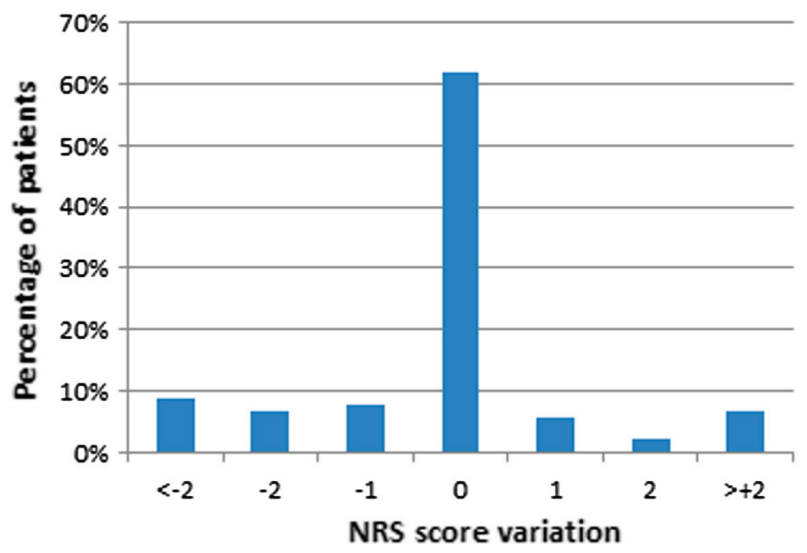

Figure 3. Change in numeric rating scale score for pain before and after treatment. The change in numeric rating scale (NRS) score for pain with respect to NRS score before treatment is illustrated for (A) within 24 hours from treatment - either after completion of treatment in local anaesthesia or before discharge from hospital in the case of general anaesthesia, (B) within 45 days from treatment, (C) after more than 45 days from treatment. $0=$ no change, $+1=$ one score up from baseline value (e.g. from NRS $=3$ to NRS $=4$ ), and likewise $-1=$ one score down.

clearly shows, that a high pain score before treatment is highly significantly correlated with pain scores after treatment; thus a very obvious recommendation would be to assess patients for pain at the first visit and institute an immediate, as well as a post-treatment and follow-up pain management plan.

Furthermore, the data analysis shows that previous irradiation to the treatment area is associated with increased risk for post-electrochemotherapy pain. Late post-surgical pain may also be a contributor, in particular for the breast cancer patients, and indeed diagnosis of breast cancer was an independently significant variable predicting pain.

A high current value was statistically correlated to pain within 24 hours from treatment $(\mathrm{p}<0.0001)$. High current values during treatment are seen when tissue is highly conductive (typically the ulcerated, necrotic cutaneous metastases), and/or when a larger part of the needle electrode is immersed in tumour tissue (i.e. exophytic or deep metastases). From this study we would not be able to answer whether the current by itself has an effect on pain after electrochemotherapy, or whether high current levels are only reflective of large and/or ulcerated metastases, which could be painful. However, large current values seen at the procedure may give an indication of expected post-treatment pain levels. Thus, in the group of 12 patients with severe pain on follow-up, $75 \%$ were treated with current levels of over $5 \mathrm{~A}$, whereas the picture was very different for the other groups.

Size of the treated cutaneous metastases (largest diameter of largest lesion) was also significantly correlated with post-treatment pain, and this again may reflect a metastasis which is larger, possibly necrotic, and with longer healing time.

Multivariate analysis was performed, and confirmed NRS pre-treatment and high current value during treatment as predictors of post-procedure pain. Also diagnoses of breast cancer and malignant 
melanoma came out as positive predictors. However, the number of patients in the analysis is small for a multivariate analysis, so these results should be interpreted with some caution.

In another study [13] increasing incidence of pain was found with repetitive treatments. Thus, increased attention should also be paid to this patient group, where progression or widespread/large cutaneous metastases necessitates several treatments. This finding would be in line with the conclusions of this study that previous treatment with radiation increases risk of pain, i.e. that the number of interventions has an impact.

In a previous publication from the INSPECT database on a cohort of 52 patients with cutaneous metastases from different tumours, pain development was reported in the area treated by electrochemotherapy 1-2 days after treatment in only five patients $(10 \%)$ [10]. Studies on melanoma patients reported no significant pain after electrochemotherapy [7], or that post-treatment pain was common but manageable with minor analgesics [14]. Other studies observed, however, that in breast cancer patients, pain was one of the major morbidities of the treatment and increased after re-treatments, reported as "moderate to severe" by $6 \%, 13 \%$ and $17 \%$ of patients after the first, second, and third application, respectively [13]. Similarly, in another study on breast cancer patients, severe pain occurred in seven patients $(44 \%)$ and in four of them, was resistant to increased dosage of opioids and lasted up to two months, with neuropathic features [12].

In this study, an important overall finding was that overall pain values were reduced after electrochemotherapy, and pain medication significantly reduced.

In conclusion, this study clearly indicates, that a group of patients at risk for pain after electrochemotherapy may be identified, and that these patients are actually identifiable at the pre-treatment visit. Although institutional guidelines and practice may vary, this guideline may serve to identify patients at risk of pain, and to plan accordingly for the patient.

What may also be learnt from this study is that post-treatment pain is not a main concern for most patients receiving electrochemotherapy, and that also this group will be identifiable by the lack of the above mentioned risk factors. Finally, our data show that pain levels and pain medication overall decrease after electrochemotherapy.

\section{Acknowledgements}

Julie Gehl was a research fellow (2009-2014) of the Royal Swedish Academy, supported by the Acta Oncologica Foundation.
Declaration of interest: IGEA (Carpi, Italy) hosts the INSPECT database, which is controlled by an independent board; the uploaded data contractually belonging to the investigators involved. Francesca de Terlizzi is an IGEA employee. Christian Kunte received honoraria for lectures and was invited to meetings by IGEA. Julie Gehl had lectures in meetings organized by IGEA, but declined honoraria. The authors alone are responsible for the content and writing of the paper.

\section{References}

[1] Belehradek M, Domenge C, Luboinski B, Orlowski S, Belehradek J, Jr., et al. Electrochemotherapy, a new antitumor treatment. First clinical phase I-II trial. Cancer 1993; 72:3694-700.

[2] Heller R, Jaroszeski MJ, Reintgen DS, Puleo CA, DeConti RC, Gilbert RA, et al. Treatment of cutaneous and subcutaneous tumors with electrochemotherapy using intralesional bleomycin. Cancer 1998;83:148-57.

[3] Sersa G, Stabuc B, Cemazar M, Jancar B, Miklavcic D, Rudolf Z. Electrochemotherapy with cisplatin: Potentiation of local cisplatin antitumor effectiveness by application of electric pulses in cancer patients. Eur J Cancer 1998; 34:1213-8.

[4] Marty M, Sersa G, Garbay JR, Gehl J, Collins CG, Snoj M, et al. Electrochemotherapy - An easy, highly effective and safe treatment of cutaneous and subcutaneous metastases: Results of ESOPE (European Standard Operating Procedures of Electrochemotherapy) study. Eur J Cancer Suppl 2006;4:3-13.

[5] Whelan MC, Larkin JO, Collins CG, Cashman J, Breathnach O, Soden DM, et al. Effective treatment of an extensive recurrent breast cancer which was refractory to multimodal therapy by multiple applications of electrochemotherapy. Eur J Cancer Suppl 2006;4:32-4.

[6] Tijink BM, De BR, Van Dongen GA, Leemans CR. How we do it: Chemo-electroporation in the head and neck for otherwise untreatable patients. Clin Otolaryngol 2006;31: $447-51$.

[7] Quaglino P, Mortera C, Osella-Abate S, Barberis M, Illengo M, Rissone M, et al. Electrochemotherapy with intravenous bleomycin in the local treatment of skin melanoma metastases. Ann Surg Oncol 2008;15:2215-22.

[8] Testori A, Rutkowski P, Marsden J, Bastholt L, ChiarionSileni V, Hauschild A, et al. Surgery and radiotherapy in the treatment of cutaneous melanoma. Ann Oncol 2009;20 (Suppl 6):vi22-9.

[9] Campana LG, Mocellin S, Basso M, Puccetti O, De Salvo GL, Chiarion-Sileni V, et al. Bleomycin-based electrochemotherapy: Clinical outcome from a single institution's experience with 52 patients. Ann Surg Oncol 2009;16: 191-9.

[10] Matthiessen LW, Chalmers RL, Sainsbury DC, Veeramani S, Kessell G, Humphreys AC, et al. Management of cutaneous metastases using electrochemotherapy. Acta Oncol 2011; 50:621-9.

[11] Curatolo P, Quaglino P, Marenco F, Mancini M, Nardo T, Mortera C, et al. Electrochemotherapy in the treatment of Kaposi sarcoma cutaneous lesions: a two-center prospective phase II trial. Ann Surg Oncol 2012;19: 192-8.

[12] Matthiessen LW, Johannesen HH, Hendel HW, Moss T, Kamby C, Gehl J. Electrochemotherapy for large cutaneous 
recurrence of breast cancer: A phase II clinical trial. Acta Oncol 2012;51:713-21.

[13] Campana LG, Valpione S, Falci C, Mocellin S, Basso M, Corti L, et al. The activity and safety of electrochemotherapy in persistent chest wall recurrence from breast cancer after mastectomy: A phase-II study. Breast Cancer Res Treat 2012;134:1169-78.

[14] Campana LG, Valpione S, Mocellin S, Sundararajan R, Granziera E, Sartore L, et al. Electrochemotherapy for disseminated superficial metastases from malignant melanoma. Br J Surg 2012;99:821-30.

[15] Mevio N, Bertino G, Occhini A, Scelsi D, Tagliabue M, Mura F, et al. Electrochemotherapy for the treatment of recurrent head and neck cancers: Preliminary results. Tumori 2012;98:308-13.

[16] Gargiulo M, Papa A, Capasso P, Moio M, Cubicciotti E, Parascandolo S. Electrochemotherapy for non-melanoma head and neck cancers clinical outcomes in 25 patients. Ann Surg 2012;255:1158-64.

[17] Campana LG, Galuppo S, Valpione S, Brunello A, Ghiotto C, Ongaro A, et al. Bleomycin electrochemotherapy in elderly metastatic breast cancer patients: Clinical outcome and management considerations. J Cancer Res Clin Oncol 2014;140:1557-65.

[18] Spratt DE, Gordon Spratt EA, Wu S, DeRosa A, Lee NY, Lacouture ME, et al. Efficacy of skin-directed therapy for cutaneous metastases from advanced cancer: A metaanalysis. J Clin Oncol 2014;32:3144-55.
[19] Escoffre JM, Rols MP. Electrochemotherapy: Progress and prospects. Curr Pharm Des 2012;18:3406-15.

[20] Kee S, Gehl J, Lee E. Clinical aspects of electroporation. New York, USA: Springer, 2011.

[21] Mir LM, Gehl J, Sersa G, Collins CG, Garbay JR, Billard V, et al. Standard operating procedures of the electrochemotherapy: Instructions for the use of bleomycin or cisplatin administered either systemically or locally and electric pulses delivered by the Cliniporator (TM) by means of invasive or non-invasive electrodes. Eur J Cancer Suppl 2006; 4:14-25.

[22] Hawker GA, Mian S, Kendzerska T, French M. Measures of adult pain:Visual Analog Scale for Pain (VAS Pain), Numeric Rating Scale for Pain (NRS Pain), McGill Pain Questionnaire (MPQ), Short-Form McGill Pain Questionnaire (SF-MPQ), Chronic Pain Grade Scale (CPGS), Short Form-36 Bodily Pain Scale (SF-36 BPS), and Measure of Intermittent and Constant Osteoarthritis Pain (ICOAP). Arthritis Care Res (Hoboken) 2011;63(Suppl 11):S240-52.

[23] Gerbershagen HJ, Rothaug J, Kalkman CJ, Meissner W. Determination of moderate-to-severe postoperative pain on the numeric rating scale: A cut-off point analysis applying four different methods. Br J Anaesth 2011;107:619-26.

[24] Heller R. Treatment of cutaneous nodules using electrochemotherapy. J Fla Med Assoc 1995;82:147-50.

[25] Curatolo P, Mancini M, Clerico R, Ruggiero A, Frascione P, Di MP, et al. Remission of extensive merkel cell carcinoma after electrochemotherapy. Arch Dermatol 2009;145:494-5. 